\title{
POBLACIÓN Y UNIDADES ECONÓMICAS COMO ELEMENTOS POTENCIALES PARA EL DESARROLLO SUSTENTABLE DE UN DESTINO TURÍSTICO. CASO COMONFORT
}

\author{
Population and economic units as potential elements for sustainable development of a tourist \\ destination. COMONFORT Case
}

\author{
Mónica Isabel Mejía - Rocha \\ Doctora en Administración. Universidad de Guanajuato, Campus Guanajuato - México, \\ monicamejia@ugto.mx
}

\begin{abstract}
Cómo citar/ How to cite
Mejía-Rocha, M. (2016). Población y unidades económicas como elementos potenciales para el desarrollo sustentable de un destino turístico. Caso Comonfort. Revista CEA, 2(3), 61-72.
\end{abstract}

Recibido: 15 de octubre de 2015

Aceptado: 30 de noviembre de 2015

\section{Resumen}

El presente trabajo, que forma parte un proyecto financiado por la SEP, a través del Programa PRODEP y cuyo proyecto se denomina «Caracterización y diagnóstico de los elementos, productos turísticos y factores del municipio de Comonfort en Guanajuato, hacia el desarrollo de un destino turístico sustentable y competitivo», muestra el resultado del análisis sobre el potencial de la población y establecimientos de servicios turísticos en una ciudad del estado de Guanajuato (México), a fin de poder determinar el potencial de estos para el desarrollo turístico sustentable del lugar. Este estudio forma parte de un diagnóstico para evaluar el potencial turístico de un destino que, aun cuando no existe información oficial sobre las perspectivas de desarrollo en este municipio (Comonfort), realizar una evaluación sobre su potencial turístico constituye una herramienta importante para los organismos encargados de dicho desarrollo, esto a fin de minimizar riesgos en posibles inversiones futuras (Zimmer y Grassmanni, 1996). Se toma, en este primer momento, como base, los datos oficiales generados por el Instituto Nacional de Estadística y Geografía (INEGI), a fin de conocer las características de la población y desenvolvimiento de los establecimientos turísticos enlistados en la ciudad de Comonfort. Se puede concluir que aun cuando no existen líneas definidas dentro del Plan de Desarrollo Turístico del estado de Guanajuato, que consideren el potencial para el desarrollo turístico sustentable de la ciudad de Comonfort al día de hoy, la ciudad cuenta con potencial en factores de gestión (recurso humano), así como factores de soporte y recursos (empresas e infraestructura), susceptibles de ser desarrollados en el municipio a fin de integrarse en la planificación de un destino turístico sustentable.

Palabras clave: población, recurso humano, turismo, economía, Comonfort, desarrollo sustentable.

\begin{abstract}
This paper presents the results of an analysis of the potential of the population and establishments of tourist services in a city in the state of Guanajuato (Mexico) in order to determine the potential of these for sustainable tourism development of the place. This study is part of a diagnosis to assess the possibilities of
\end{abstract}


tourism of a destination for which -even though there is not any official information on the prospects of development in this municipality (Comonfort)- conducting an assessment of possibilities of tourism is an important tool for agencies working on this field, in order to minimize possible risks in future investments (Zimmer and Grassmanni, 1996). Initially, on a first attempt, his study uses official data generated by the National Institute of Statistics and Geography (INEGI) in order to know the characteristics of the population and the evolution of tourist establishments listed in the city of Comonfort. It can be concluded that even if there are not any defined lines within the Tourism Development Plan of the State of Guanajuato that include the potential for sustainable tourism development in the city of Comonfort today, the city has potential management factors (human resources) and supporting factors and resources (enterprises and infrastructure), likely to be developed in the municipality to be integrated into the planning of a sustainable tourist destination.

Keywords: population, human resources, tourism, economy, Comonfort, sustainable development.

\section{INTRODUCCIÓN}

El turismo es considerado como un elemento detonador para el desarrollo socioeconómico de los pueblos. Esta actividad, en constante evolución, reporta cada vez más destinos emergentes. El turismo llega en algunos contextos a igualar y, en otros casos, a superar las exportaciones de la industria petroquímica, alimentaria y automotriz. La Organización Mundial del Turismo (OMT, 2015) asegura que el turismo sustentable beneficia a los países en vías de desarrollo, contribuyendo de manera significativa en la atenuación de la pobreza. A nivel mundial, esta actividad en el año 2014 generó el $10 \%$ del Producto Interno Bruto reportando 1.133 millones de llegadas de turistas internacionales, lo cual generó uno de cada once empleos y 1.5 billones de dólares en exportaciones, contribuyendo en el $6 \%$ del comercio internacional y en el $30 \%$ de las exportaciones de servicios.

En el 2014, la región de las Américas registró el mayor crecimiento en llegadas de turistas internacionales (8\%); México se reincorporó al grupo de los diez primeros países por llegadas de turistas internacionales con una captación de divisas de 16 mil 257.9 millones de dólares, avanzando 14 posiciones en el Ranking de Competitividad de Viajes y Turismo (WEF).

Para México, el turismo es un sector prioritario, pues contribuye en el $8.7 \%$ del PIB nacional. Asimismo, contribuye satisfactoriamente en la generación de empleo, debido a que en el año 2014 empleó a casi 2.3 millones de personas, es decir, el $8.1 \%$ de los puestos laborales generados en ese año, permitiendo la participación activa de casi el $54.8 \%$ de las mujeres en sus plantillas de personal (CSTM, 2015).

El turismo debe desarrollarse en forma sustentable y competitiva a fin de que se logre satisfacción y lealtad del turista, impactando favorablemente a las localidades que lo reciben. El turismo debe ser siempre un factor de desarrollo sostenible para las comunidades donde se practica, esto queda claro en el Artículo 3, del Código de Ética del Turismo.

El Plan Nacional de Desarrollo, 2013 - 2018, dentro de sus ejes prioritarios de desarrollo, considera: "potenciar la actividad turística en el país a fin de generar mayores ingresos, a través de la diversificación, desarrollo y promoción de nuevos destinos» (Peña, 2013). La Secretaría de Turismo (SECTUR), con la Secretaría de Medio Ambiente y Recursos Naturales (SEMARNAT), desarrolló el programa de Agenda 21 para el turismo mexicano, cuyo esquema de trabajo propone estrategias y acciones a fin de fortalecer las dinámicas turísticas de manera sustentable, consolidando el bienestar de las personas, respetando el medio ambiente y optimizando beneficios económicos y sociales de las comunidades (Martínez y Ruiz, 2009). 
Para la planificación de un destino turístico sustentable es necesario realizar, al menos, un diagnóstico de sus atributos únicos, que, utilizados de manera sustentable, le permitan al destino en cuestión mostrar competitividad en el mercado turístico. Estos atributos pueden analizarse desde cuatro ejes principales: Ventaja comparativa, Orientación de la demanda, Estructura de la industria y Compromiso ambiental (Hassan, 2000 y Poggi y Ferrera, 2006). Para identificar el potencial turístico sustentable de un destino, se puede considerar el modelo propuesto por Ritchie y Crouch (2003), que consideran cinco factores integradores en estos destinos: factores amplificadores 0 restrictivos; de política, planeación y desarrollo; de gestión; de atracción y de soporte y recursos.

De lo anterior, resulta considerable realizar un diagnóstico sobre los atributos únicos del municipio de Comonfort, localidad en desarrollo, del estado de Guanajuato; identificar y analizar de qué manera la población y la economía de este municipio han evolucionado de acuerdo con las cifras oficiales en México, a fin de poder coincidir con los puntos que permitirán en el momento de su desarrollo, como destino turístico, la inclusión de la mano de obra disponible en dicha entidad.

El objetivo de trabajo realizado consistió en caracterizar a la población del municipio de Comonfort, así como la evolución de las unidades de negocio turísticas existentes, a fin de ser considerados estos elementos como factores de gestión (recursos humanos) y de soporte (empresas turísticas) para el potencial de desarrollo turístico de un lugar.

\section{MARCO CONTEXTUAL}

En México la actividad turística muestra cifras favorables, pues en el 2015 se calculó que arribaron al país cerca de 32 millones de turistas internacionales, 9.2\% más que en 2014, generando una derrama económica (o ingresos provenientes de la actividad de turismo) estimado en 17 mil 500 millones de dólares, mostrando un incremento del $11.1 \%$ en la balanza turística y generando, además, un poco más de tres millones de empleos directos, principalmente para jóvenes y mujeres (SECTUR, 2016).

La Secretaría de Turismo en México reconoció al estado de Guanajuato como el destino a nivel nacional más visitado, por encima de los destinos de playa. La derrama económica generada en el estado, por esta actividad, mostró una tendencia favorable del año 2012 con 53 mil millones de pesos; en el año 2014 se registraron 72 mil millones de pesos, cifra que representa el $9 \%$ del Producto Interno Bruto y que refleja su importancia en la generación de empleo, colocándose como el segundo sector más importante en cuanto a dicha generación, estimando 176 mil empleos directos, con un impacto a 500 mil personas aproximadamente.

El municipio de Comonfort, del estado de Guanajuato, fue fundado en el año 1591 por los españoles con el nombre de San Francisco Chamacuero. En 1861 fue declarado municipio y en 1874 , por decreto estatal, se le denominó Chamacuero de Comonfort. Representa el 1.6\% de la superficie total del estado de Guanajuato, con $485.90 \mathrm{~km}$. El municipio hace frontera con los siguientes municipios del mismo estado: al Norte con San Miguel de Allende, al Sur con Celaya, al Este con Apaseo el Grande y al Oeste, Santa Cruz de Juventino Rosas (Fig. 1).

El municipio de Comonfort se encuentra colindando con entidades que han mostrado comportamientos favorables en su desarrollo turístico, es decir, las ciudades de Celaya y San Miguel de Allende; lo anterior, se suma al impulso de la actividad turística que se está generando en el estado y país, siendo importante la valoración y planificación de los factores estratégicos para un futuro desarrollo turístico en esta entidad. 


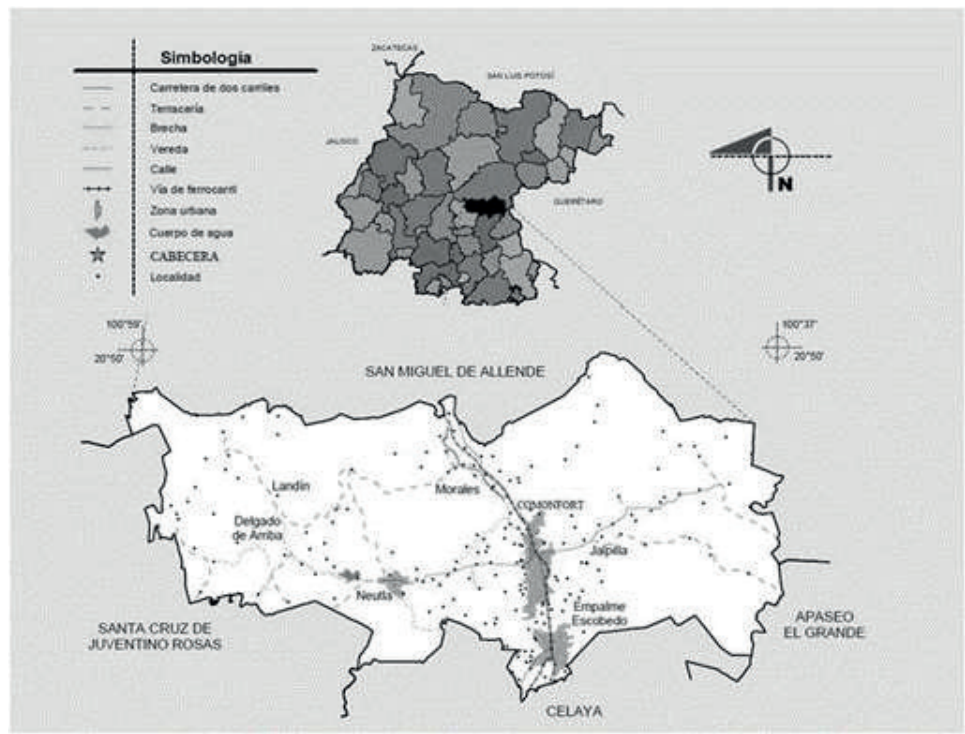

Figura 1. Ubicación del Municipio de Comonfort- Guanajuato

Figure1. Territorial location Comanfort- Quanajuato

Fuente: INEGI. Compendio de información geográfica municipal.

\section{MARCO TEÓRICO}

En el contexto occidental, el turista visto como miembro de una corriente masiva, se asocia de manera directa con el desarrollo económico y tecnológico de las sociedades que visita (Bringas y Ojeda, 2000). La estrecha asociación entre el turismo y el desarrollo local supone que los actores son los beneficiarios directos, y que la cultura es el principal sostén para movilizar las energías locales de un destino dado. Las dimensiones del desarrollo local que impactan en dicha actividad serán al menos: social, de identidad, económica, productiva y política (Montero, 2004).

El turismo sustentable, según la Organización Mundial del Turismo, refiere a los proyectos turísticos que en su planificación y desarrollo consideran las repercusiones actuales y futuras, económicas, sociales y medioambientales, al satisfacer los requerimientos del turista, de la industria, del entorno y de las comunidades anfitrionas.

Los principios que definen al turismo sustentable:
- La conservación de los elementos naturales y culturales para su uso actual y futuro

- Resguardar el equilibrio ambiental y sociocultural del destino receptor

- Mantener y evolucionar la calidad ambiental

- Elevar el nivel de satisfacción de los visitantes

- La repartición justa de los beneficios del turismo entre los actores sociales de la sociedad receptora

Estos principios se definen a fin de que la actividad turística de un destino dado se considere como una herramienta estratégica en el desarrollo tanto local, regional y nacional. La actividad turística requiere de grandes inversiones en equipo e infraestructura, además de una densa mano de obra, pues este sector ofrece grandes oportunidades de empleo y negocio, tanto para jóvenes, mujeres y hombres (OMT, 1993).

Dentro del contexto del turismo responsable y sostenible, la OMT y ONU (1999), emitieron el Código de ética del turismo, donde se promulgan líneas de acción, a fin de garantizar la magnificencia de los beneficios del sector en las 
sociedades. Los componentes económico, social, cultural y ambiental del turismo, se han englobado en diez artículos.

El artículo primero, en su tercer apartado, se refiere a la formación y profesionalización necesaria por parte de la comunidad receptora, a fin de proporcionar al visitante un trabajo hospitalario. En el apartado cinco, del segundo artículo, se habla sobre la flexibilización que deberá de existir en la inclusión de programas de estudio y formación, acorde con la enseñanza del valor de los intercambios turísticos, de sus beneficios y riesgos. El artículo quinto, alude a la implicación de las comunidades locales en las actividades y empleos directos generados por el turismo y sus beneficios; el penúltimo artículo, el noveno, centra su atención en el establecimiento y aplicación de políticas públicas que favorezcan la inserción laboral de las personas de las comunidades que muestren calificación suficiente, y en caso contrario, generar la posibilidad de esta formación para su pronta incorporación en el mercado turístico laboral.

Para la planificación y desarrollo de destinos turísticos existen varios modelos que se perfilan hacia la competitividad y sustenibilidad. Ritchie y Crouch (2003) han propuesto un modelo de "Competitividad y sostenibilidad para destinos turísticos», dicho modelo considera dos ambientes, el macro o global y el micro o competitivo; además de enlistar cinco factores para tales alcances:

- Factores amplificadores o restrictivos (localización, seguridad, costo/valor, interdependencia, conciencia / imagen y capacidad).

- Factores de política, planeación y desarrollo (definición del sistema, filosofía y valores, visión del destino, posicionamiento, desarrollo, análisis de competencia/colaboración, monitoreo/evaluación y auditoría).

- Factores de gestión (organización, mercadotecnia, calidad del servicio/experiencia, información y búsqueda, desarrollo de recurso humano, finanzas, gestión de visitantes, administración de los recursos y gestión de crisis.

- Factores de atracción (fisiografía y clima, cultura e historia, vínculos de mercado, mix de actividades, eventos especiales, entretenimiento y superestructura).

- Factores de soporte y recursos (infraestructura, accesibilidad, recursos facilitadores, hospitalidad, empresas y voluntad política).

En los anteriores se puede observar la gran variedad de aspectos integradores de un destino turístico en desarrollo con un sentido sustentable y competitivo. La población de un destino turístico dado debe ser el candidato ideal para integrarse en la plantilla laboral de las empresas turísticas del lugar que den servicio a sus turistas y visitantes.

Los agentes turísticos actuales, tanto privados como públicos, deben organizar la gestión de los flujos turísticos y la organización de los destinos desde una visión coherente, integradora y cualitativa, a fin de poseer la capacidad de planear, coordinar y regular sistemas en donde sus actores se beneficien del turismo y contribuyan de diversas maneras a subsanar el desgaste que dicha actividad genere en la población anfitriona (Mazaro y Varzin, 2008). El turismo sustentable, como tal, según la UNESCO, debe garantizar la permanencia ecológica del lugar a largo plazo, ser viable en lo económico y ético en lo social (UNESCO, 2009).

Los territorios y países subdesarrollados deben considerar al turismo como una estratégica opción para la valoración de sus elementos potenciales (naturales, históricos, culturales, económicos) y por ende para su desarrollo, tanto en el ámbito local como regional. El desarrollo local supone la mejoría de las condiciones de una localidad o nación, previendo la participación representativa de los pobladores del lugar con relación a los extranjeros, a fin de que estos como actores principales, los residentes del destino sean los beneficiarios directos $y$ principales del fenómeno turístico. 
Desde inicios del presente siglo, el turismo ha mostrado una tendencia en la desconcentración y reorientación hacia nuevas opciones de turismo, permitiendo el surgimiento de nuevos destinos. Esta diversificación responde en mucho a los intereses del viajero actual que presenta especial interés en descubrir alternativas variadas para la práctica del turismo, estas nuevas tendencias son denominadas generalmente como turismo alternativo. Esta emergente tipología turística refiere a la opción de los turistas a incluirse activamente en la apreciación y disfrute de los elementos del patrimonio natural y cultural de una comunidad, sea esta rural, indígena o urbana (Ibáñez y Rodríguez, 2012), así como el surgimiento de nuevos destinos para el desarrollo de la actividad turística.

El anfitrión o local de un destino turístico juega un papel importante al colocarse en esta dinámica como objeto de exhibición y transmisión de los elementos materiales que identifican la cultura de su lugar (Sánchez, 2014), sugiriendo la evolución cultural del hombre en su aspecto individual y social (Molina, Rodríguez y Cuamea, 1986).

El crecimiento acelerado del turismo dinamiza el progreso socioeconómico de las naciones, impactando favorablemente en términos económicos y de empleos directos e indirectos. La Asamblea General de las Naciones Unidas (ONU) ha delineado los Objetivos de Desarrollo Sustentable de las Naciones (17), dentro de estos lineamientos el turismo es considerado como un elemento estratégico para el desarrollo sustentable de los pueblos. Tres de los diecisiete objetivos se refieren a:

- Principio 8, reconoce la importancia de impulsar el desarrollo económico, sostenible e inclusivo del trabajo y empleo para todos.

- Principio 12, se centra en el consumo y producción sustentable de todos sus elementos y productos de los pueblos y naciones.
- Principio 14, habla sobre el uso y conservación responsable y sostenible de los mares, océanos y recursos marítimos.

El primero, aquí enlistado, habla sobre la importancia de la evolución económica de las naciones a través del turismo, con la generación de empleo en los destinos $y$, además, que debe darse accesibilidad a las sociedades donde se desarrolle dicha práctica. Este mismo organismo ha proclamado el 2017 como el año internacional del turismo sostenible para el desarrollo, siendo esta una oportunidad especial para el beneficio de los elementos de sustentabilidad para las naciones, tanto en lo económico, social y medio ambiental (OMT, 2015).

\section{RESULTADOS}

Como resultado del análisis de información estadística, generada por el Instituto Nacional de Estadística y Geografía (INEGI), se realizaron varios análisis a fin de poder obtener la información relativa a población y empresas (unidades económicas) turísticas (sector 72), para posteriormente generar los resultados de este trabajo.

De acuerdo con el Directorio de Unidades Económicas (DENUE - INEGI, 2015), el número de establecimientos registrados en Comonfort, en el año 2014, fue de 2433 unidades, de las cuales el $9.97 \%$ se clasifican dentro de los establecimientos de Servicios de alojamiento temporal y de preparación de alimentos y bebidas. Aun cuando el municipio cuenta con este tipo de establecimientos, no existe evidencia de un Plan de Desarrollo Turístico.

En el Censo Económico 2014, se pudo conocer el desarrollo de los subsectores que impactan en el desarrollo de la economía en el municipio de Comonfort, considerando las ediciones 2004, 2009 y 2014 (Tabla 1). 
Tabla 1. Evolución de las unidades económicas en Comonfort (2004 - 2014)

Table 1. Evolution of economic units in Comonfort (2004-2014)

\begin{tabular}{|l|c|c|c|}
\hline Año / Municipio / Sector / Subsector & $\begin{array}{c}\text { Unidades } \\
\text { económicas }\end{array}$ & $\begin{array}{c}\text { Unidades } \\
\text { económicas }\end{array}$ & $\begin{array}{c}\text { Unidades } \\
\text { económicas }\end{array}$ \\
\hline 11009 Comonfort & 2004 & 2009 & 2014 \\
\hline 21 Minería & 1.599 & 1.761 & 2.433 \\
\hline $\begin{array}{l}\text { 22 Generación, transmisión y distribución de energía eléctrica, } \\
\text { suministro de agua y de gas por ductos al consumidor final }\end{array}$ & $*$ & $*$ & $*$ \\
\hline 23 Construcción & $*$ & $*$ & 5 \\
\hline 31 -33 Industrias manufactureras & 122 & 140 & 235 \\
\hline 43 Comercio al por mayor & 32 & 30 & 42 \\
\hline 46 Comercio al por menor & 981 & 1.052 & 1.348 \\
\hline $48-49$ Transportes, correos y almacenamiento & 17 & $*$ & $*$ \\
\hline 51 Información en medios masivos & 4 & 7 & 4 \\
\hline 52 Servicios financieros y de seguros & 10 & 12 & 15 \\
\hline 53 Servicios inmobiliarios y de alquiler de bienes muebles e intangibles & 43 & 36 & 51 \\
\hline 54 Servicios profesionales, científicos y técnicos & 26 & 27 & 37 \\
\hline $\begin{array}{l}\text { 56 Servicios de apoyo a los negocios y manejo de desechos y servicios } \\
\text { de remediación }\end{array}$ & 17 & 36 & 66 \\
\hline 61 Servicios educativos & 8 & 12 & 13 \\
\hline 62 Servicios de salud y de asistencia social & 40 & 64 & 82 \\
\hline $\begin{array}{l}\text { 71 Servicios de esparcimiento culturales y deportivos, y otros servicios } \\
\text { recreativos }\end{array}$ & 14 & 19 & 38 \\
\hline $\begin{array}{l}\text { 72 Servicios de alojamiento temporal y de preparación de alimentos y } \\
\text { bebidas }\end{array}$ & 129 & 147 & 230 \\
\hline 721 Servicios de alojamiento temporal & 5 & 6 & 6 \\
\hline 722 Servicios de preparación de alimentos y bebidas & 124 & 141 & 224 \\
\hline 81 Otros servicios excepto actividades gubernamentales & 152 & 173 & 262 \\
\hline
\end{tabular}

Fuente: elaboración propia a partir de INEGI. Censos económicos 2014.

Sistema Automatizado de Información Censal (SAIC).

Como se puede observar en la Tabla 1, las unidades económicas en el municipio de Comonfort han incrementado su número en los diez años comprendidos entre el 2004 y 2014; los subsectores económicos que han mostrado mayor crecimiento han sido el comercio al menor, los servicios mobiliarios $y$, afortunadamente para el sector turístico, aun cuando no se ha declarado de manera oficial un desarrollo en este sentido en este municipio, los servicios de preparación de preparación de alimentos y bebidas que se han incrementado en casi 100\%, es decir, de 124 establecimientos registrados en el año 2004, en el año 2014 se cuentan con 224. Lo anterior muestra un indicio de la manera en la que este sector ha dado no solo dinamismo a la economía de la entidad, sino también generador de empleos para el desempeño de estos productos y servicios (Tabla 2). 
Tabla 2. Tendencia del personal remunerado por sector económico (2004 - 2014)

Table 2. Trend paid workforce by economic sector (2004 - 2014)

\begin{tabular}{|c|c|c|c|}
\hline Año / Municipio / Sector / Subsector & $\begin{array}{c}\text { Personal } \\
\text { remunerado } \\
\text { total }\end{array}$ & $\begin{array}{c}\text { Personal } \\
\text { remunerado } \\
\text { total }\end{array}$ & $\begin{array}{c}\text { Personal } \\
\text { remunerado } \\
\text { total }\end{array}$ \\
\hline & 2004 & 2009 & 2014 \\
\hline 11009 Comonfort & 1.550 & 1.692 & 2.833 \\
\hline 21 Minería & 23 & 10 & 12 \\
\hline $\begin{array}{l}22 \text { Generación, transmisión y distnbución de energía eléctrica, suministro de agua y de } \\
\text { gas por ductos al consumidor final }\end{array}$ & 44 & 56 & 31 \\
\hline 23 Construcción & 4 & 134 & 189 \\
\hline 31-33 Industrias manufactureras & 408 & 323 & 1.398 \\
\hline 43 Comercio al por mayor & 198 & 102 & 42 \\
\hline 46 Comercio al por menor & 381 & 588 & 553 \\
\hline 48-49 Transportes, correos y almacenamiento & 17 & 9 & 21 \\
\hline 51 Información en medios masivos & 2 & 12 & 3 \\
\hline 52 Servicios financieros y de seguros & 41 & 31 & 134 \\
\hline 53 Servicios inmoblianos y de alquiler de bienes muebles e intangibles & 35 & 45 & 14 \\
\hline 54 Servicios profesionales, cientificos y técnicos & 20 & 21 & 26 \\
\hline 56 Servicios de apoyo a los negocios y manejo de desechos y servicios de remediación & 20 & 30 & 37 \\
\hline 61 Servicios educativos & 121 & 63 & 103 \\
\hline 62 Servicios de salud y de asistencia social & 26 & 51 & 49 \\
\hline 71 Servicios de esparcimiento culturales y deportivos, y otros servicios recreativos & 8 & 9 & 8 \\
\hline 72 Servicios de alojamiento temporal y de preparación de alimentos y bebidas & 102 & 122 & 134 \\
\hline 721 Servicios de alojamiento temporal & 2 & 1 & 15 \\
\hline 722 Servicios de preparación de alimentos y bebidas & 100 & 121 & 119 \\
\hline 81 Otros servicios excepto actividades gubemamentales & 100 & 86 & 79 \\
\hline
\end{tabular}

Fuente: elaboración propia a partir de INEGI. Censos económicos 2014.

Sistema automatizado de información censal (SAIC).

En la tabla que antecede, se puede observar que aun cuando de manera general el incremento de personal ocupado y remunerado ha incrementado casi cerca del $100 \%$, solo son tres subsectores que han mostrado el mismo comportamiento en cuanto incremento, pero no porcentaje, pues los servicios de alojamiento y preparación de alimentos y bebidas han incrementado dicha plantilla en un casi $25 \%$. De acuerdo con la Tabla 1, se puede asegurar que el incremento en el número de unidades económicas no es directamente proporcional al incremento del personal ocupado en dicho establecimiento.
En el análisis sobre la tasa de desempleo en los municipios del Estado, hecho a fin de conocer el comportamiento del municipio de Comonfort (ver tabla 3), se pudo observar que, aun cuando en la media se ha registrado un incremento en la tasa de desempleo, llegando en el 2010 al 5,4\%, el municipio de Comonfort mostro un índice del $6,6 \%$, superior a la media, empero este mismo comportamiento se observó en los municipios considerados como destinos turísticos en el Estado, como San Miguel de Allende, que presentaron una tasa de desempleo del 7,3\%. 
Tabla 3. Tasa de desempleo en los municipios del Estado (1990 - 2010)

Table 3. Unemployment rate in the municipalities of the State (1990 - 2010)

\begin{tabular}{|c|c|c|c|}
\hline & 1990 & 2000 & 2010 \\
\hline Guanajuato & 3 & 1,2 & 5,4 \\
\hline A basolo & 2,1 & 0,9 & 4,7 \\
\hline A cámbaro & 4,2 & 1,6 & 8,4 \\
\hline San Miguel de Allende & 2,2 & 1 & 7,3 \\
\hline A paseo el Alto & 3,2 & 1,7 & 7,8 \\
\hline Apaseo el Grande & 2,8 & 1,1 & 6,1 \\
\hline A tarjea & 3,1 & 1,4 & 2,6 \\
\hline Celaya & 2,4 & 1,1 & 4,9 \\
\hline Manuel Doblado & 3,3 & 0,6 & 4,9 \\
\hline Comonfort & 2,6 & 1 & 6,6 \\
\hline Coroneo & 2,5 & 0,7 & 6,5 \\
\hline Cortazar & 2,7 & 1,2 & 5,3 \\
\hline Cuerámaro & 3,5 & 0,8 & 16,2 \\
\hline Doctor Mora & 4,6 & 0,7 & 7,9 \\
\hline $\begin{array}{l}\text { Dolores Hidalgo Cuna de la } \\
\text { Independencia Nal. }\end{array}$ & 2,2 & 0,9 & 5,5 \\
\hline Guanajuato & 1,9 & 1,1 & 5,5 \\
\hline Huanimaro & 3,6 & 1,3 & 9,2 \\
\hline Irapuato & 2,5 & 1,1 & 5,3 \\
\hline Jaral del Progreso & 5,7 & 1,5 & 9,1 \\
\hline Jerécuaro & 4,7 & 1 & 12 \\
\hline León & 1,7 & 1 & 4,3 \\
\hline Moroleón & 3,4 & 0,9 & 5,6 \\
\hline Ocampo & 4,8 & 1,1 & 8 \\
\hline Pénjamo & 4,8 & 1,4 & 6,1 \\
\hline Pueblo Nuevo & 2,8 & 1,9 & 5,1 \\
\hline Purís ima del Rincón & 1,4 & 0,6 & 1,6 \\
\hline Romita & 3,3 & 1,7 & 3,9 \\
\hline Salamanca & 6,6 & 2,1 & 6,8 \\
\hline Salvatierra & 4,9 & 2,1 & 5,5 \\
\hline San Diego de la Unión & 4 & 0,5 & 7,3 \\
\hline San Felipe & 3,2 & 1,1 & 6,3 \\
\hline San Francisco del Rincón & 2 & 0,6 & 2,1 \\
\hline San José Iturbide & 3,2 & 0,9 & 5,4 \\
\hline San Luis de la Paz & 5,4 & 1,3 & 8 \\
\hline Santa Catarina & 10,3 & 0,7 & 8,9 \\
\hline $\begin{array}{l}\text { Santa Cruz de Juventino } \\
\text { Rosas }\end{array}$ & 2,3 & 1,9 & 7,3 \\
\hline Santiago Maravatio & 11,6 & 2,4 & 10,1 \\
\hline Silao & 2,3 & 0,9 & 5,9 \\
\hline Tarandacuao & 3,2 & 1,2 & 3,3 \\
\hline Tarimoro & 4,6 & 1 & 6,5 \\
\hline Tierra Blanca & 4,3 & 2,7 & 3,8 \\
\hline Uriangato & 3,8 & 1,3 & 4,8 \\
\hline Valle de Santiago & 6,4 & 2,1 & 5,9 \\
\hline Victoria & 4,8 & 1 & 7,4 \\
\hline Villagrán & 3,3 & 0,8 & 6,2 \\
\hline Xichú & 2,6 & 0,1 & 1,3 \\
\hline Yuriria & 3 & 1,2 & 5,9 \\
\hline
\end{tabular}

Fuente: elaboración propia a partir de INEGI. Indicadores de la serie censal 1990 a 2010. 
En cuanto al crecimiento de su población, el municipio de Comonfort ha casi que quintuplicado su crecimiento del año 1900 al 2010 (Fig. 2).

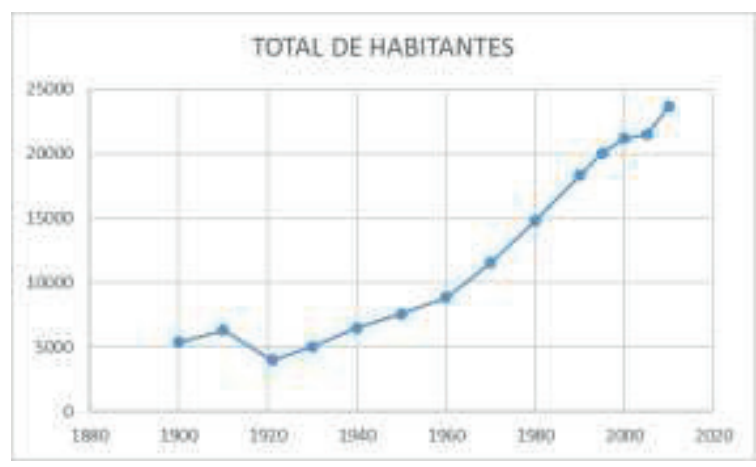

Figura 2. Crecimiento en número de la población de Comonfort (1900 - 2010)

Figure 2. Population growth of Comonfort (19002010

Fuente: elaboración propia a partir de Censos Poblacionales INEGI.

En la Fig. 2 se puede observar que aun cuando en el año 1920 se registró un descenso en el número de habitantes del municipio de Comonfort, en relación con el año inmediato anterior, el crecimiento se ha dado de manera paulatina y constante, dato que de manera proporcional se ha mostrado, pero en sentido contrario, hacia el incremento de personal desempleado.

\section{CONCLUSIONES}

El presente trabajo nos ha permitido conocer que el municipio de Comonfort cuenta con una población económicamente activa, similar en comportamiento a varios municipios del Estado y de los destinos turísticos, lo cual nos permite suponer que un posible proyecto de desarrollo turístico en la entidad es factible, desde la dimensión de la mano de obra, para la comercialización de turismo a través del servicio.

En lo que refiere a factores de soporte y recursos, considerando las empresas turísticas existentes en la ciudad, se puede decir que existe un crecimiento significativo en el número de unidades económicas que centran sus funciones en la preparación, venta y distribución de alimentos, así como las que brindan servicio de hospedaje temporal. Esto es importante pues, aun cuando no existe un plan de desarrollo turístico oficial para este municipio, el hecho de que este tipo de unidades económicas se vayan incrementando refiere que la actividad turística se da en aumento, pues la demanda de estos servicios ha llevado al incremento de la oferta.

En cuanto a elementos de factores de gestión, el municipio de Comonfort cuenta con mano de obra suficiente para un desarrollo turístico planificado. Cabe mencionar que existe ya personal originario del municipio laborando en las empresas existentes que prestan servicios turísticos en Comonfort. Es importante considerar la formación profesional del recurso humano, una vez que se implemente un desarrollo de manera oficial, pues la calidad depende en mucho de la profesionalización de las personas que trabajan en el sector.

Muy probablemente el desarrollo del turismo en esta entidad permitiría mayor número de personas involucradas en esta actividad, y por tanto en favor de impactar de manera favorable la población en los índices de desempleo de la misma.

El presente trabajo permitió conocer, además, que el municipio cuenta con las bases suficientes, desde la perspectiva social y de empleo, a fin de promover un desarrollo turístico sustentable con la generación de empleos equitativos, justo y ético para sus pobladores.

\section{REFERENCIAS}

Bringas, N. y Ojeda, L. (2000). El ecoturismo: ¿una nueva modalidad del turismo? Revista de Economía, Sociedad y territorio, 11(7), 373-403. Recuperado de http://www.redalyc.org/articulo.oa?id=1110 0701

Gobierno del Estado de Guanajuato (2015). Reconoce la SECTUR a Guanajuato como el 
Sexto Estado más visitado de la República Mexicana. Recuperado de http://noticias.guanajuato.gob.mx/2015/10/ 28/reconoce-la-sectur-a-guanajuato-comoel-sexto-estado-mas-visitado-de-larepublica-mexicana/

Hassans, S. (2000). Determinants of Market Competitiveness in an environmentally sustainable tourism industry. Journal of Travel Research, 38(3), 239-245. Recuperado de http://jtr.sagepub.com/content/38/3/239.s hort

Ibáñez, R. y Rodríguez, V. I. (2012). Tipologías y antecedentes de la actividad turística: turismo tradicional y turismo de aventura. Recuperado de http://www2.inecc.gob.mx/publicaciones/li bros/669/tipologias.pdf

INEGI (s.f.). Evolución histórica territorial de los municipios del Estado de Guanajuato. México.

INEGI (1997). División territorial del Estado de Guanajuato de 1810 a 1995. Aguascalientes, México.

INEGI (2014). Censos Económicos 2014. Sistema automatizado de información censal (SAIC). Recuperado de http://www3.inegi.org.mx/olap/olap.aspx?s erver $=2 \& d b=$ Serie_Censal_Economicos $\& c u$ be $=$ Censos $\% 20$ Econ\%C3\%B3micos\&fp $=1$

Instituto Nacional para el Federalismo y el Desarrollo Municipal. Gobierno del Estado de Guanajuato (2000). Enciclopedia de los municipios de México: Estado de Guanajuato. Recuperado de http://www.elocal.gob.mx/work/templates/enciclo/guana juato/index.html

Mara, M. R. y Varzin, G. (2008). Modelos de Competitividad para destinos turísticos en el marco de la sostenibilidad. RAC, Curitiba (12), 789-809. Recuperado de http://www.scielo.br/pdf/rac/v12n3/09.pdf
Martínez, O. y Ruiz, J. (2009). Las particularidades de la Agenda 21 para el turismo mexicano. Un análisis de la aplicación del sistema de indicadores de sustentabilidad en el municipio de playas de Rosarito B. C., México. Gestión Turística, 12, 9-29. Recuperado de http://mingaonline.uach.cl/pdf/gestur/n12/ art01.pdf

Molina, S. y Rodríguez, W. M. y Cuamea, F. (1986). Turismo alternativo en acercamiento crítico y conceptual. México: Trillas.

Montero, J. C. (2004). Desarrollo local y actividad turística. Aportes y transferencias. Centro de Investigaciones Turísticas. UNM1P, 8(1), 1138.

OMT (s.f.). Sustainable Development of Tourism. Recuperado de http://sdt.unwto.org/es/content/definicion

OMT (2015). Las Naciones Unidas proclaman 2017 Año Internacional del Turismo Sostenible para el Desarrollo. Recuperado de http://media.unwto.org/es/pressrelease/2015-12-10/las-naciones-unidasproclaman-2017-ano-internacional-delturismo-sostenible

OMT (2015). La OMT se congratula de la adopción de los Objetivos de Desarrollo Sostenible. Madrid, España. Recuperado de http://media.unwto.org/es/pressrelease/2015-09-29/la-omt-se-congratulade-la-adopcion-de-los-objetivos-dedesarrollo-sostenib

OMT (2015). ¿Por qué turismo? Recuperado de http://www2.unwto.org/es/content/porque-el-turismo

ONU (2015). Objetivos de desarrollo sostenible. 17 Objetivos para transformar nuestro mundo. Recuperado de http://www.un.org/sustainabledevelopment les/

ONU y OMT (2001). Código de ética del turismo. Recuperado

de 
http://dtxtq4w60xqpw.cloudfront.net/sites/ all/files/docpdf/gcetbrochureglobalcodees.p df

Poggi, M. y Ferreira, M. (2006). Competitividad y Turismo Sustentable. El caso de Aguas de San Pedro. Estudios y Perspectivas en Turismo, (15), 220-235. Recuperado de http://www.scielo.org.ar/scielo.php?script= sci_arttext\&pid=S1851-

17322006000300002

Ritchie, J. R. y Crouch, G.I. (2000). The competitive destination: a sustainability tourism perspective. UK: Cromwell Press.

Ritchie, J.R. y Crouch, G.I. (2003). The competitive destination. Wallingford: $C A B$ International Publishing.

SECTUR, Guanajuato (2015). Desarrollo de la industria turística en Guanajuato durante el 2014. Observatorio Turístico. Recuperado de http://www.observatorioturistico.org/public aciones

SECTUR (2015). Comunicado de Prensa 89. Dirección General de Comunicación Social. Recuperado de http://www.sectur.gob.mx/sala-deprensa/2015/05/21/boletin-89-turismosector-estrategico-para-la-economiamexicana/

SECTUR (2015). Comunicado de Prensa 33/2015. Dirección General de Comunicación Social. Recuperado de http://www.sectur.gob.mx/sala-deprensa/2015/02/15/boletin-33-alcanzamexico-record-en-captacion-de-divisas-viaturismo-internacional-durante-2014/

SECTUR (2015). Comunicado de Prensa 15/2015. Dirección General de Comunicación Social. Recuperado de http://www.sectur.gob.mx/sala-deprensa/2015/01/22/boletin-15-mexico-esel-segundo-pais-mas-importante-enturismo-de-america-por-su-fortaleza-eninfraestructura/
SECTUR (2015). Logros del sector turismo en México. Recuperado de http://www.gob.mx/sectur/videos/logrosdel-sector-turismo

SECTUR (2015). Recibe México en 2015 a más de 31 millones de turistas internacionales: Enrique de la Madrid. Prensa. Recuperado de https://www.gob.mx/sectur/prensa/recibemexico-en-2015-a-mas-de-31-millones-deturistas-internacionales-enrique-de-lamadrid

NOTIMEX (2016). El turismo en México con potencial para alcanzar el crecimiento económico sostenido: EMC. Prensa. Recuperado de http://www.notimex.com.mx/acciones/nota Comunicado.php?clv=398884

SECTUR (2016). Este 2016 el turismo se consolidará como uno de los principales motores de la economía. EMC. Prensa. Recuperado de http://www.datatur.sectur.gob.mx/SitePage s/NoticiasdelSector.aspx

UNESCO (2009). Sustainable Tourism Development in UNESCO Designated Sites in South - Eastern Europe. Training the Trainers Programme, Regional Bureao of Science, and Culture in Europe. Recuperado de http://portal.unesco.org/es/files/45338/124 17872579Introduction_Sustainable_Tourism .pdf/Introduction_Sustainable_Tourism.pdf

Zimmer, P. y Grassmanni, S. (1996). Evaluar el potencial turístico de un territorio. Leader II. Recuperado de http://ec.europa.eu/agriculture/rur/leader2 /rural-es/biblio/touris/metho.pdf

Sánchez, L. M. (2014). La población como protagonista de la difusión del patrimonio cultural. NORBA-ARTE, (24), 189-200. Recuperado de file://C:/Users/Monica/Downloads/DialnetLaPoblacionLocal-2282633.pdf 